\title{
The study of carbon monoxide placenta blood hemoglobin oxygenation Chen Chen ${ }^{1, a}$, Xiang Wang ${ }^{1, b, *}$, Pei Wang ${ }^{1, c}$, Donglai $\mathrm{Qi}^{1, \mathrm{~d}}$
}

Tianjin Polytechnic University, school of environment and chemical engineering Tianjin, 300387, China

acchentpu@yeah.net, ${ }^{b}$ tpuwx@163.com, ${ }^{c} 15822829856 @ 163 . c o m,{ }^{d}$ ferretqi@126.com

Keywords: hemoglobin, $\mathrm{RBC}, \mathrm{HbCO}, \mathrm{HbO} 2$.

\begin{abstract}
With the great progress of hemoglobin-based blood substitutes, however, theyallhave a same problem that is hard to get effective stable structure of hemoglobin. The hemoglobin can be oxidized into met hemoglobinin the process of purification,lead to the loss of the function of carrying and transporting oxygen. The combination of $\mathrm{CO}$ and placenta blood hemoglobin ability is far higher than that of $\mathrm{O} 2$, the structure and properties of carbon monoxide hemoglobin $(\mathrm{HbCO})$ has more stable.Red blood cell (RBC)is mixed with organic solvent for hemolysis and centrifuged for removal of stroma.To prevent $\mathrm{MetHb}$ formation during the procedure, $\mathrm{Hb}$ was carbonylated in advance.Excessive carbon monoxide pumped to hemoglobin,hemoglobin is converted intoHbCO. $\mathrm{HbCO}$ is decarbonylated to regenerate $\mathrm{HbO} 2$ by exposing the solution to oxygen and visible light, the content of HbCOand HbCOis measured by blood gas analyzer.By comparing the liquid membrane and film boiling method, determination of oxygenation results.Measured liquid membrane oxygenation ismore effective than hollow fiber module method.Through the liquid membrane method, large quantities of hemoglobin can be treated in production, it also can reduce the loss of hemoglobin during purification,increase oxygen affinity.
\end{abstract}

\section{Introduction}

The development of hemoglobin-based blood substitutes has now advanced to the stage that several products are being tested in clinical trial [1-2]. These studies, as well as numerous animal studies, have demonstrated that the administration of relatively large quantities of extracellular hemoglobin or hemoglobin derivatives may lead to a variety of undesirable toxic side effects [3].It has been known for more than a decade that the administration of native hemoglobin causes severenephrotoxicity's, which are apparently associated with the excretion of hemoglobin dimers via the kidneys.Initially,it was suggested that at least some of these toxic effects may be due to impurities that remained present in the various hemoglobin preparations, such as endotoxins and/or stromal phospholipids [4-6].It is proposed that this limitation can be overcome byincreasing molecular size and oxygen affinity.We have established a new method by taking the advantage of excellent stability of carbonylhernoglobin $(\mathrm{HbCO})$, then remove $\mathrm{CO}$ from $\mathrm{Hb}$ before purification.

\section{Materials and methods}

Preparation of stroma-free $\mathrm{HbCO}$

Washing hemoglobin:RBCs were obtained from Tianjin union stem cell gene engineering company. The placenta blood was put into centrifugal tube, Volume should not exceed 1/3 of centrifuge tube,added the physiological saline to two-thirds of the centrifugal tube, centrifuged by high-speed centrifuge table $\left(\geq 2,800 \mathrm{~g}, \leq 15 \mathrm{~min}, 4^{\circ} \mathrm{C}\right)$. Thesupernatant was removed after the end of centrifugation, repeat the process 3 to 5 times until the supernatant was close to colorless.

Carbonylation: The washed blood was transferred to the conical flask, added an equal volume of saline to dilute. The $\mathrm{CO}$ was pumped into the bloodstream by syringe needle, the time was about 30 min, and the whole process would find that the color of the blood changed from red to dull-red.The solution was centrifuged by high-speed centrifuge table $\left(\geq 2,800 \mathrm{~g}, \leq 15 \mathrm{~min}, 4^{\circ} \mathrm{C}\right)$, the supernatan was removed after the end of centrifugation. 
Membrane remove: first, the centrifugal solution $(\mathrm{RBC})$ was put into the ice water to cool to $4^{\circ} \mathrm{C}$, then, $\mathrm{RBC}$ was mixed with $\mathrm{CH}_{2} \mathrm{Cl}_{2}$ for hemolysis, the volume of $\mathrm{RBC}$ and $\mathrm{CH} 2 \mathrm{Cl} 2$ is 1:0.2. The mixed solution was shaken for $3 \mathrm{~min}$ and then centrifuged $(28,000 \mathrm{~g}, 15 \mathrm{~min})$. An $\mathrm{HbCO}$ solution was separated as a top layer. After repeating the procedure again, residual $\mathrm{CH}_{2} \mathrm{CI}_{2}$, in the $\mathrm{HbCO}$ solution was removed out at ca. 20 torr at $40^{\circ} \mathrm{C}$ in dark.

The oxygen of $\mathrm{HbCO}$

Method 1:hollow fiber module method

$\mathrm{COHb}$ solution was frown through hollow fiber module, with the condition of light, ice water bath, oxygen, $\mathrm{CO}$ was removed from $\mathrm{HbCO}$ solution, it is purposed to stabilize hemoglobin.

Scheme 1:Blood goes around hollow fiber, the oxygen goes into the hollow fiber.

$20 \mathrm{ml} \mathrm{NaHCO} 3$ was added into the $40 \mathrm{ml}$ removed membrane solution to accommodate $\mathrm{pH}$. The $\mathrm{pH}$ of $\mathrm{HbCO}$ was 8.25. According to Bohr Effect: with the loss of the $\mathrm{pH}$ value, the oxygen affinity of hemoglobin was receded. So control $\mathrm{pH}$ of $\mathrm{HbCO}$ fluid for weak alkaline. The test was started in a bottle,the content of $\mathrm{HbCO}$ and $\mathrm{HbCO}$ is measured by blood gas analyzer.

Scheme 2: Change the way of oxygen and blood circulation mode, other conditions are not changed. The oxygen goes around hollow fiber, blood goes into the hollow fiber.

Method 2:liquid membrane method

To make $\mathrm{HbCO}$ solution forming a very large area of liquid membrane on the surface, the gas exchange area of $\mathrm{HbCO}$ was increased, it is more favorable for $\mathrm{CO}$ and $\mathrm{O} 2$ exchange.

Scheme 1: pumping in oxygen and evacuated replacement

$\mathrm{NaHCO}_{3}$ was added into the $80 \mathrm{ml}$ removed membrane solution to accommodate $\mathrm{pH}$. The $\mathrm{pH}$ of $\mathrm{HbCO}$ was 7.8. The $\mathrm{HbCO}$ solution was transferred into an eggplant shaped bottle after $\mathrm{pH}$ adjustment, connected to the rotary evaporation apparatus for oxygenation in the condition of light and ice water bath. the whole process of experiment was need to access to oxygen, need a vacuum after 10 min oxygen flux, continuously repeating the experiment operation, every once in a while after taking $3 \mathrm{ml} \mathrm{HbCO}$ solution, diluted with $20 \mathrm{ml}$ distilled water, with $0.22 \mu \mathrm{m}$ membrane filter. The content of $\mathrm{HbCO}$ and $\mathrm{HbO}_{2}$ were measured by blood gas analyzer.

Scheme 2: In combination with oxygen and evacuated replacement

Phytic acid $0.76 \mathrm{~g}$ and $0.76 \mathrm{~g}$ ascorbic acid were dissolved in $40 \mathrm{ml}$ distilled water, adjusted the $\mathrm{pH}$ to 7.5 , mixing with $40 \mathrm{ml}$ removed membrane solution. In the $80 \mathrm{ml}$ mixed solution, the final concentration of phytic acid was $10 \mathrm{mmol} / \mathrm{L}$, the final concentration of ascorbic acid was $5 \mathrm{mmol} / \mathrm{L}$. The mixed solution was transferred into an eggplant shaped bottle, connected to the rotary evaporation apparatus, and only used its rotation function for oxygenation with the condition of light and ice water bath. At the beginning of the experiment, the mixed solution was, then pumped in oxygen $10 \mathrm{~min}$, vacuumized $10 \mathrm{~min}$. Continuously repeating the experiment operation, every once in a while after taking $3 \mathrm{ml} \mathrm{HbCO}$ solution, diluted with $20 \mathrm{ml}$ distilled water, with $0.22 \mu \mathrm{m}$ membrane filter. The content of $\mathrm{HbCO}$ and $\mathrm{HbO}_{2}$ were measured by blood gas analyzer.

\section{Results and analysis}

\section{1 The result of hollow fiber module method}

The result of scheme 1: 

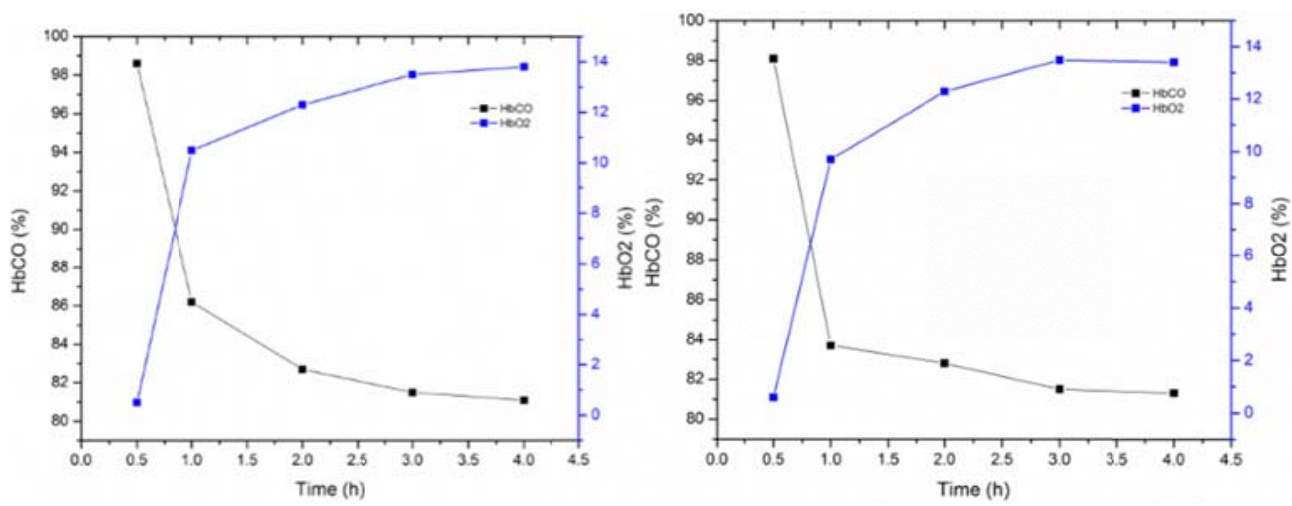

Fig.1. Speed of transformation from Fig.2. Speed of transformation from

$\mathrm{HbCO}$ to $\mathrm{HbO}_{2} \mathrm{HbCO}$ to $\mathrm{HbO}_{2}$

At the beginning of reaction, the percentage of $\mathrm{HbCO}$ fell sharply, as the experiment progresses, the speed decreases, three hours later, thepercentage was no longer droped, eventually remained at around $82 \%$, and the percentage $\mathrm{ofHbO}_{2}$ increased slowly.

The result of scheme 2 :

Though the way of oxygen and blood circulation mode had beenchanged, the HbCOsolution can contact with more sufficient oxygen, but on the whole the results did not have a material impact, the percentage of $\mathrm{HbCO}$ still no longerdroped after $81 \%$.

By comparing the results of two schemes, the process of experiment was taken by two different ways, but got the same results. Two experimental schemes finally measured the percentage of $\mathrm{HbCOwas}$ around $81 \%$, cannot be further reduced. Method ofhollow fiber module does not apply to HbCOoxygenation.

\section{2. Theresult of liquid membrane method}

The result of scheme 1:

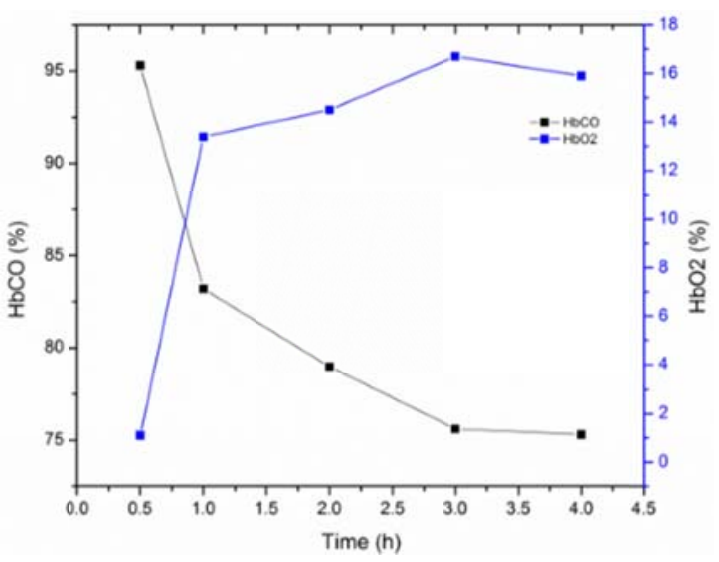

Fig.3. Speed of transformation from $\mathrm{HbCO}$ to $\mathrm{HbO}_{2}$

It had no longer a significant change untilthe percentage ofdropped to about $78 \%$. By figure 3 wefound that the percentage of $\mathrm{HbCO}$ fell fast within the starting $2 \mathrm{~h}$, but after reaction for $2 \mathrm{~h}$, the percentage of HbCOkept balance, there had no reduction.

The result of scheme 2 : 


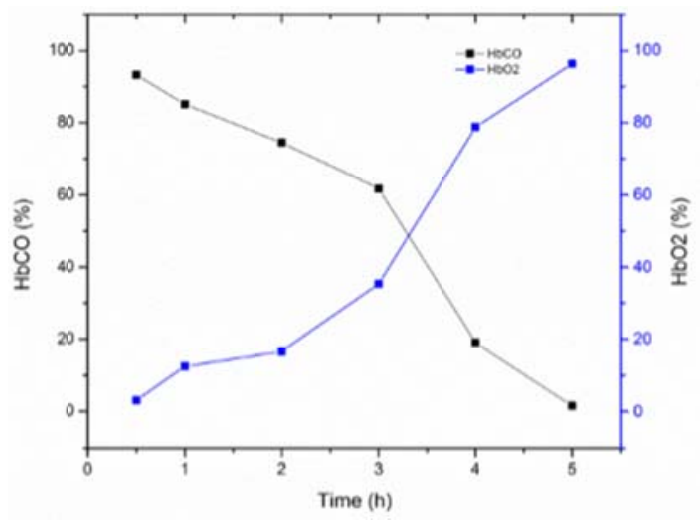

Fig.4. Speed of transformation from $\mathrm{HbCO}$ to $\mathrm{HbO}_{2}$

Aswe could see from figure 4, the percentage of $\mathrm{HbCO}$ dropped to $1.5 \%, \mathrm{HbO} 2$ in quantity from $3.1 \%$ to $96.4 \%$, and the percentage ofincreased quickly, $\mathrm{HbCO}$ wasconverted to $\mathrm{HbO}_{2}$ within $5 \mathrm{~h}$. The metHb was $3.1 \%$.

By comparing the results of two schemes, we found thatthe phytic acidwas of a similar effect with2, 3 - DPG, it can combineHband promote the release of oxygen. Vc wasa strong reducibility, Hbcould not been oxidized to high iron statusduring experiment process.

\section{Conclusion}

With the result of two methods, there had a conclusion that liquid membrane method (in combination with oxygen and evacuated replacement) was more effective than hollow fiber module method. Hb could keep more stable and increase oxygen affinity by using liquid membrane method in oxygenation experiment. It has a significant preparation for $\mathrm{Hb}$ purification.

\section{References}

[1] G. A, "Recent advances in the development of haemoglobin-based blood substitutes," Expert opinion on investigational drugs, vol. 6, 2005.

[2] C. T. M, "Cross-linked hemoglobins being well into clinical trials, increasing research efforts are now on a second generation red blood cell substitute based on encapsulated hemoglobin," Artificial cells, blood substitutes, and immobilization biotechnology, vol. 23, 1995.

[3] M. Feola, J. Simoni, P. C. Canizaro, R. Tran, G. Raschbaum, and F. J. Behal, "Toxicity of polymerized hemoglobin solutions," Surgery, gynecology \& obstetrics, vol. 166, pp. 211-22, 1988Mar 1988.

[4] F. M, S. J, C. P. C, T. R, R. G, and B. F. J, "Toxicity of polymerized hemoglobin solutions," Surgery, gynecology \& obstetrics, vol. 166, 1988.

[5] B. R, S. D, M. G, B. G, and D. F, "Hematologic effects of hemoglobin solutions in animals," Progress in clinical and biological research, vol. 122, 1983.

[6] S. J, F. M, and C. P. C, "Generation of free oxygen radicals and the toxicity of hemoglobin solutions," Biomaterials, artificial cells, and artificial organs, vol. 18, 1990. 